\title{
Environmental Health Literacy Promotion Within The TCU Campus Community
}

SOPHIE DOHNALEK

May 4, 2016 


\section{ABSTRACT}

An emerging field, environmental health literacy (EHL) aims to equip the public with information and risk communication tools that are applicable and easily understood. This study aimed to determine whether environmental health (EH) education impacts student, faculty, and staff's likelihood to reduce or stop the use of products that are known to negatively impact health. To address the need for improved EHL, education sessions to promote EHL took place on an urban private university campus among students, faculty, and staff. Students, faculty, and staff on the TCU campus participated in an EH education session. Pender's (1982) Health Promotion Model and evidence from the Agency for Toxic Substances and Disease Registry (ATSDR) informed session development. Each session consisted of a presentation, hands-on demonstration, and group discussion. Participants completed baseline surveys, and discussion questions were recorded and transcribed. The investigator used descriptive and content analysis methods to evaluate these data. Twenty-seven participants (17 students, 10 faculty/staff) attended one of five group sessions. Of those, 81.5\% reported no prior EH education; however, 77.8\% indicated awareness of natural alternatives. An estimated 95\% of participants felt the lesson motivated them to make informed choices and educate others. Key barriers to applying EHL in daily life included lack of understanding and education on the topic (37\%), cost (33.3\%), and brand familiarity (26\%). Education sessions promoted EHL among students, faculty, and staff. These sessions have the potential to improve understanding of $\mathrm{EH}$, and the overall health of the community by empowering individuals to make informed choices.

Environmental health (EH) and environmental health literacy (EHL) are concepts identified by the American Nurses Association as important guidelines to nursing practice, but these guidelines are rarely addressed in the public or clinical settings (ANA, 2007). EHL raises awareness among the general public about the health risks associated with environmental exposures, particularly sources that come from individuals' product use in the home (National Institute of Environmental Health Sciences [NIIEHS], 2014). Uninformed decisions when choosing household cleaning products and personal care products can lead to short-term effects, such as skin and eye irritation and respiratory issues, as well as long-term health consequences, including infertility and neurodevelopmental disorders in children (ATSDR, 2017; Banerjee \& Sangupta, 2014; Lanphear, 2015). Although initiatives exist to reduce exposure, environmental health literacy remains low among the US population (Barrett et al., 2015; Brown et al., 2011; Glegg \& Richards, 2007). Providing education and improving environmental health literacy may equip individuals with the information necessary to effect personal and community change. The purpose of this project is to evaluate an environmental health education session among students, faculty, and staff on the Texas Christian University campus, to enhance environmental health literacy and allow individuals to participate in health promoting behavior by pursuing safer options for personal care and household cleaning products.

\section{STATEMENT OF CLINICAL QUESTION}

The principal aim of this study is to determine whether environmental health education impacts participants' likelihood to reduce or stop the use of products that are known to negatively impact health. The population includes students, faculty, and staff on the Texas Christian University (TCU) campus.

\section{THEORETICAL FRAMEWORK}

The theoretical framework for this study was Pender's Health Promotion Model (Appendix A). This model suggests that well-being is dynamic, not solely relying on the presence or absence of disease (Pender, 1982). Health is defined as individual potential achieved through setting goals, providing self-care, and engaging in positive relationships with others (Pender, 1982), while illness is an acute or chronic state that negatively impacts an individual's ability to achieve health (Pender, 1982). The model explores the individual's experiences, interaction with the environment, and the impact these interactions have on well-being. In this model are five central concepts: person, environment, nursing, health, and illness.

Pender defines the person as a biopsychosocial being that can be changed and shaped by the environment. In this study, the person is defined more broadly as a population of students, faculty members, and staff at TCU. The environment, defined by Pender as the social, cultural, and physical factors in life that can be manipulated, is the TCU 
campus in this study. To achieve the principal aim of this study, nursing action is defined as environmental health education and activities implemented to produce a higher level of well-being.

The components of this model are divided into individual characteristics and experiences, and behavior-specific cognitions and affect. Pender defines the theoretical variables as follows: individual characteristics and experiences include prior related behavior, or how frequently an individual has repeated a health behavior in the past, and personal factors, which include age, race, personality, ethnicity, and economic status (Pender, 1982). Behavior-specific cognitions and affect include perceived benefits of action, perceived barriers to action, perceived self-efficacy, activity-related affect, interpersonal influences, situational influences, commitment to a plan of action, and immediate competing demands and preferences. The desired outcome is health-promoting behavior.

Operational definitions for this study will follow the format Pender developed. Personal factors will include age, gender, and major. Prior related behavior is the frequency with which the participants use or are exposed to environmental toxins. Perceived benefits and barriers to action are the participants' own beliefs on why health promotion may benefit or harm them, and the costs they associate with these health behaviors. Perceived self-efficacy refers to the participants' own views on how capable and confident they feel in participating in the health promoting behavior. Activity-related affect is the participants' feelings or attitudes toward the health promoting education before, during, and after carrying out the intervention. Interpersonal influences will focus on campus peers and family influences on the participants' perceptions toward environmental health, and their likelihood to carry out health promoting behaviors described in the education session. Situational influences are the participants' perceptions of how the health behaviors they are taught can be integrated into their environment on a college campus and at home. Commitment to a plan of action will be evident in the participants' intentions to participate in risk-reducing behavior in their natural environments. Immediate competing demands and preferences are the factors that vie for the participants' time and attention over health promotion, such as social obligations or heavy workload. These factors will be determined through a baseline survey and a follow-up discussion after education.

The research question and theoretical framework led to an extensive literature review to better understand the concepts underlying environmental health literacy and the impact of environmental health on adults, including those of college age and beyond.

\section{REVIEW OF LITERATURE}

The investigator utilized the databases Medline Complete, CINAHL Complete, and ERIC. Search terms consisted of the following: environmental toxins, environmental health, personal care, household, cleaning, knowledge, university, college, and health promotion. These search terms were broad enough to yield a variety of results, limited to research from 2006 to the present in order to focus on up-to-date information. The inclusion criteria consisted of English language, research conducted in the United States, and college or adult age, so that the results would be relevant to the target population. The exclusion criteria were any samples of an age less than 18 years.

\section{ENVIRONMENTAL HEALTH OVERVIEW}

The reciprocal relationship between environmental health and human health is well-documented. Corvalán, Kjellström, and Smith (1999) attempted to explain the discrepancies between estimates of the effect the environment has on human health by defining the terms environmental, ill health, and attributable. Although dated, the information is relevant in determining the effect the environment plays on disease burden in the global community. The authors concluded that the environment plays a major role both directly and indirectly on human health. Based on data obtained from poor and middle-income countries, it is clear that activities in the wealthiest countries are the most threatening to the global environment (Corvalán et al., 1999). The study identifies the need for community environmental control efforts and a better-coordinated effort to collect data on environmental exposures related to health. 
Bondi (2010) explored the precautionary principle as it applies to consumer household cleaning products, particularly sanitizers and disinfectants. The precautionary principle is defined by Raffersperger and Tickner (1996) as follows: "when an activity raises the threat of harm to human health and the environment, precautionary measures should be taken even if some cause and effect relationships are not fully established scientifically" (p. 429). At the policy level, application of the precautionary principle establishes that a chemical with uncertain environmental or human health impacts should not be available for purchase or use. When the effects of the ingredient are known and can be mitigated, the ingredient can be used after a research and mitigation strategy is implemented (Bondi, 2010).

Although the precautionary principle has the potential to reduce exposure to negative health and environmental effects of chemicals, this approach is believed by some to stifle innovation (Kriebel et al., 2001). However, Bondi (2010) determined that when applied to thymol, an EPA registered botanical disinfectant, the precautionary principle actually encouraged innovation rather than stifling it, and provided consumers with a natural household disinfectant that poses low risk to environmental and human health. The safety profile of thymol has been thoroughly researched, as thymol is an essential oil of the Thymus vulgaris (thyme) plant, which has been used and tolerated well by humans throughout history. The anti-microbial effects of thymol have also been well established, making it an appropriate natural alternative to conventional household disinfectants (Edris, 2007; Xu et al., 2008). The risk of thymol is the potential to cause skin irritation common among essential oils, but this irritation is dose dependent (Bondi, 2010). Through a research and mitigation process, a formulation of thymol $0.05 \%$ was shown to be non-toxic to land and aquatic life, and it met the microbiological requirements for EPA registration as a disinfectant. In addition, when exposing 54 human participants to thymol $0.05 \%$, only one participant was shown to have skin irritation resulting from application (Bondi, 2010). As this article demonstrates, exercising the precautionary principle has the potential not only to prevent harmful exposures, but also to promote innovation in the production of green household cleaning products.

\title{
ENVIRONMENTAL HEALTH LITERACY
}

\author{
Environmental health literacy (EHL) is an emerging and evolving concept that bridges shared theories from the \\ fields of risk communication, environmental health science, behavioral science, evaluation, communications, public \\ health, and the social sciences. The process of becoming environmentally health literate entails raising scientific \\ literacy, environmental literacy, and numeracy among the general public while increasing awareness of specific \\ exposures and their potential health effects (NIEHS, 2014).
}

EHL aims to equip the public with information and risk communication tools that are applicable and easily understood. EHL encompasses aspects of risk communication, health literacy, environmental health sciences, communications research, and safety. Finn and O'Fallon (2015) provide an overview of EHL and its past, present, and future significance. Risk communication has the deepest historical root, tracing back to ancient symbols various cultures would use to indicate danger, like a skull and crossbones to identify poison. These symbolic representations of danger or toxic situations were further established as effective risk communicators in World War II and the nuclear energy threat in the 1950s (Finn and O'Fallon,2015). Symbolic representations were particularly effective because people did not need to know how to read to understand the signs. The late 20th century sparked new developments in EHL, when it was widely recognized that environmental exposures could pose health risks but had varying toxicities. New symbols had to be made to indicate varied toxicities, thus encouraging development of EHL through more effective risk communicators.

Svertson (2015) aimed to explore the influence of mapped environmental hazards on the dependent variables of risk belief, emotion, intention to change behavior, and roles of risk beliefs and emotion in mediating these influences among college students. This qualitative study included interviews with participants and collected survey responses to 6 maps showing environmental water hazards, chosen at random from a selection of 24 maps. 
A previous study aimed to discover participants' perceptions when looking at maps of a fictitious water hazard in private residential wells (Severtson \& Vatovac, 2012). The maps were either cluster or distance maps, with dots representing affected wells clustered around the participant's home or at a certain distance away, respectively. The sample consisted of undergraduate psychology, sociology, and nursing students in Madison, Wisconsin, ages 17$44,92 \%$ of whom were Caucasian. Students were verbally invited by researchers to participate in the survey and of the 1,045 students invited, 446 returned completed surveys. Survey responses showed that on both distance and cluster maps, hazard level and distance had moderate to large impacts on dependent variables, including susceptibility to hazards of contaminated wells, locational social comparison (one's risk compared to others in the area), how serious the problem is, distress over risk, monitor intentions (participants' desire to test drinking water), and mitigate intentions (participants' desire to avoid drinking from affected wells) (Severtson \& Vatovac, 2012). The most significant influence of this study was that of hazard level on perceived susceptibility. This finding supports the need for further research, as having an understanding of potential health hazards in personal care and cleaning products increases perceived susceptibility, thus encouraging individuals to seek out more information and make individual changes.

Dixon, Dixon, Hendrickson, Ercolano \& Quackenbush (2009) aimed to develop and validate an environmental health survey that assesses ways in which people engage in environmental health issues. This study utilized a qualitative approach in three phases. The first phase included interviews with participants in order to develop survey content; the second phase was a review of the survey content by experts, and the third phase was giving the survey to participants to complete. The survey consisted of 14 items representing Pollution Types and Actions and 18 items representing Concerns. The participants rated questions on a scale from 0-10, 0 meaning no problem, 10 indicating a serious problem. The results showed that participants perceived a connection between environment and health problems, but showed low scores on personal action. In addition, younger participants had greater concerns about pollution and the effect on health than the older participants. This is consistent with research conducted showing that, relative to older adults, young people see increased risks to self and family from environmental health hazards (Cutchin et al., 2008).

Glegg and Richards (2007) aimed to explore the barriers preventing European citizens from purchasing "green" household products. The study utilized non-experimental, descriptive and non-experimental explanatory research methods in a three-stage methodology. The three-stages included an exploratory phase, a descriptive questionnaire, and focus groups. Results from the study showed that of 1,008 randomly selected respondents, $50 \%$ of 18 to 24 year olds said they never consider the environmental impact when choosing cleaning products, compared to $35.7 \%$ of 55 to 64 year olds. This indicates that older age groups have a higher level of environmental awareness, which may suggest a "failure of the education system to inculcate environmental values that would create consumers who are aware of the effects of personal behaviour on the environment" (Glegg \& Richards, 2007, p. 898). Results showed $22.3 \%$ of participants indicated poor product information was a major barrier to buying low impact products. Researchers noted "It was clear participants bought and used products despite a general acceptance that they may cause harm to health and the environment" (Glegg \& Richards, 2007, p. 896). Targeting individual concern by creating awareness for environmental issues was identified as a potentially successful way to market green products. Because the environment is often perceived as a "commons," it is difficult for individuals to understand the personal benefits of protecting the environment (Glegg et al., 2007). For this reason, educating students, faculty, and staff on a university campus has the potential to promote understanding of environmental issues so as to decrease use and exposure to potentially hazardous household products.

\section{EHL AMONG COLLEGE STUDENTS}

College students are a particularly significant population to target when considering EHL, as young people are concerned about health risks associated with environmental health hazards (Cutchin et al., 2008). Focusing on this population may equip students with the knowledge to participate in health promoting behaviors and reduce exposures throughout the course of their lifetime. This not only impacts this population's health, but also the health of their children and subsequent generations. By employing EHL strategies and providing environmental health education, investigators may prepare college students to promote EHL and effect change among local and global communities. 
Brown et al. (2011) sought to assess college students' knowledge, attitudes, and associated behaviors in regard to environmental health. This study utilized a nonexperimental, quantitative design, and data was collected via survey containing 36 items that measured knowledge, attitudes, and behaviors associated with environmental health. Knowledge questions were multiple choice, while attitudes and behaviors used a Likert-type scale ranging from 1 (strongly disagree) to 4 (strongly agree). Experts in environmental health ensured validity of the survey using Delphi rounds. The participants consisted of 395 undergraduate students in a Midwest university, the majority of whom were female and in their freshman year. Results showed a significant knowledge deficit, as the majority of participants answered only 4 of the 11 knowledge questions correctly (Brown et al., 2011). It is important to note that these results may be due to the high number of freshmen that participated in the study.

A higher level of knowledge indicated a more favorable attitude toward environmental health issues questions like home planning, sustainability, and water quality, although most participants had a positive attitude on these issues overall. Higher attitude scores tended to predict a person's likelihood to engage in behaviors that reduce environmental health risks (Brown et al., 2011). These behaviors may include using fewer potentially hazardous cleaning products, personal care products, and participating in activities that reduce emissions of $\mathrm{t}$ oxins. The authors concluded that educators must play a role in discussing environmental health issues, helping $\mathrm{w}$ to raise risk awareness through hands-on activities that foster a mental connection between knowledge and behavior change.

Barrett, Chan, and Chalupka (2015) examined the perceptions of female college students regarding toxins in personal care products, as well as their effect on preconception health. The study utilized a non-experimental, descriptive research method. Variables included the quantity, variety, and frequency with which personal care products were used in a 24-hour period, and awareness that exposure can impact preconception health. A questionnaire was distributed via e-mail that included open and closed-ended questions about personal care products and preconception health. Seventy-two participants were drawn from female-dominated majors at the university, including nursing, psychology, and communication science disorders; inclusion criteria included age of 18-24 years, non-pregnant, and English-speaking. The results of the study revealed $69 \%$ of participants used at least 11 products (toothpaste, deodorant, soap, shampoo, hand sanitizer, lotion, lip balm, foundation, mascara, eyeliner) on a daily basis. Hand sanitizer (64\%), lip balm (24\%), and soap (17\%) were the top three high-use products. Many students (46\%) disagreed that they were exposed on a daily basis at home to toxic products, but $51 \%$ were concerned about the effect of exposure on health, and 31\% desired to obtain more information on safety and regulations (Barrett et al., 2015). This study indicates a gap in knowledge regarding everyday toxins and their impact on current and future health, supporting the need for further research. Providing college students, faculty, and staff with information on the dangers of everyday toxins and ways to reduce exposure may effect change by promoting healthier options both at home and in the community.

\section{SUMMARY}

Based on the literature reviewed, lack of environmental health literacy impacts individuals' ability to effect change and choose health promoting behaviors, such as buying less harmful personal care and cleaning products. In fostering the acquisition of knowledge and positive behaviors and attitudes toward environmental health, there is potential to influence individual change, which may have lasting impacts on campus and in the community. As more students and faculty understand their individual impact on environmental health, these individuals can use collective action and advocacy to influence campus administrators and community leaders to alter policy to encourage fewer exposures. This effort will not only benefit current students' health, but also the health of students for years to come through diffusion of innovation.

The Diffusion of Innovation (DOI) Theory (Appendix B) is a social science theory developed by E.M. Rogers (1962). DOI explains how ideas gain momentum over time, resulting in change on a larger scale within social systems. The theory identifies five groups: innovators, early adopters, early majority, late majority, and laggards. The theory relies on five factors that influence whether an innovation is adopted. These factors are relative advantage (is it better than the previous concept?), compatibility (is it consistent with existing values and needs?), 
complexity (is it difficult to understand?), triability (can you experiment with it before committing to change?), and observability (are there tangible results?). Through EH education, students are equipped with information that allows them to be early adopters and diffuse information within the TCU campus community. Education sessions that highlight the five influencing factors of innovation can be highly effective. Sessions should highlight the relative advantage of EHL, present information that is compatible with existing values, provide a simple explanation of EHL, and use demonstration to prove triability and observability in order to promote DOI among participants.

Pender's Health Promotion Model will help to guide this research in identifying participants' perceived benefits, barriers, self-efficacy, and activity related affect toward environmental health. Ideally, providing knowledge on the topic and giving information on risk reducing behaviors will increase the perceived benefits, self-efficacy, and activity related affect, resulting in a commitment to a plan of action (Pender, 1982).

This study may encourage participants to educate others on environmental health impacts, thus equipping them with information necessary to prevent potential health complications. Next steps include identifying environmental health hazards present on TCU's campus, discovering any negative health outcomes that can result from these, and implementing teaching via education sessions on environmental health.

\section{METHODS}

\section{Implementation}

After literature review, the researcher identified gaps in EHL and created an EH education session to improve EHL among the target population. The education sessions utilized a mixed-methods, cross-sectional study design. The researcher received IRB approval from TCU.

\section{Recruitment}

The population included students, faculty, and staff over the age of 18 years, who were enrolled or employed at Texas Christian University in Fort Worth, Texas. Participants needed to speak and comprehend English in order to participate because the researcher's native language is English, and available materials were written in English. Because this was an exploratory study, English speakers were recruited for the purpose of efficiency. The researcher recruited 27 participants who attended one of 5 education sessions.

The researcher recruited students, faculty, and staff on a voluntary basis, using recruitment materials approved by the IRB. To recruit students, the researcher made an announcement at various campus group meetings at Texas Christian University. The researcher introduced herself, identified her affiliations (TCU nursing student), and asked the individuals if they would like to participate. Faculty investigators made an announcement in class about the study, providing a sign-up sheet for students who were interested. Investigators could offer extra credit to students who participated if they so choose. To recruit faculty and staff, the researcher circulated the flyer via e-mail and postings in high traffic areas (break room and mail room).

Those who were not interested in participating in the study were not be pressured to participate. The researcher asked those who were interested in participating to provide their contact information, so that they would receive an information sheet and consent document via e-mail that further explained the study. After completing the informed consent process, the participants selected a session that they would like to attend. The voluntary nature of the study was emphasized throughout the recruitment and enrollment process.

\section{Data Collection}

Data came from a baseline survey, as well as a group discussion. Baseline surveys included demographic questions and basic questions about personal care product and household cleaning product use. Demographic questions included age, gender, education level, major/discipline, marital status, number of children, and any relevant health conditions (cardiovascular, respiratory, gastrointestinal, renal, neurological, musculoskeletal, other, 
with a brief definition of the organs included in each system to ensure participants understanding).

Additional survey items assessed potential exposure to chemicals in products used regularly. Participants used an ordinal scale to indicate how many personal care and household cleaning products they use on a daily basis (0-3 products, 3-5 products, 5-7 products, 7-10 products). Participants were then asked to list the products they used daily. In addition, the survey asked participants if they had received previous education about potential hazards in personal care and household cleaning products, and if they had heard of or considered using natural alternatives to these products.

After the EH education session, the researcher asked five questions to evaluate the extent to which participants met the learner objectives: participants' understanding of the lesson, their desire to apply the information, and any barriers that may prevent them from applying EHL in daily life when purchasing products. The researcher recorded responses on the Lecture Recorder app, available through the App Store? for MacBook目, and transcribed responses for analysis.

\section{EH Education}

Each session lasted 60 to 90 minutes, and consisted of a baseline survey, education, demonstration, and a group discussion. Participants completed the baseline survey in approximately 10 minutes. The presentation lasted 20-30 minutes in PowerPoint format, adapted from materials available through the Agency for Toxic Substances and Disease Registry (2017). Objectives for participants included: expressing new perceptions about environmental health and the value of environmental health awareness in society, identifying potentially hazardous effects of various products, identify barriers to purchasing "natural" or "green" products, demonstrating how to make a household cleaner using essential oils, and committing to replace one household cleaning or personal care product with a green alternative. The outline consisted of an overview of environmental health in society, commonly used personal care and cleaning products, and the health and environmental implications of these products.

Halfway through the presentation, the researcher provided participants with a brief demonstration on the use of essential oils, water, and vinegar to create a natural countertop spray at home. Participants used the recipe to build their own solutions in a spray bottle to take home. A folder containing information on alternative personal care products and cleaning products, resources for more information, and recipes for at-home products was provided after instruction. Resources in the folder included the Environmental Working Group (EWG) Guide to Healthy Cleaning, as well as the EWG Skin Deep Database (EWG, 2017). In the follow-up period after instruction, the researcher asked questions about the session, inquiring about the changes they might make, the perceived barriers, and their opinion on the effectiveness of the lesson.

\section{Data Analysis}

After collection of the survey data, the researcher transferred all data obtained on the survey form to an Excel spreadsheet for statistical analysis. Univariate descriptive statistics (means, standard deviations, and percentages were used to describe the overall sample's completion of the objectives. Using the digital recording of each session, the researcher transcribed participant responses verbatim. Responses were compiled by relevant word, phrase, or theme and analyzed using methods of content analysis.

\section{Results}

Results are reported as follows: a description of the sample characteristics of the target population, product use among participants, prior EH education and baseline knowledge, reported barriers, and expressed commitment to action. Tables are included at the end of each subsection for reference.

\section{Sample Characteristics}

Demographic information obtained from baseline surveys is shown in Table 1. The majority of participants $(62.9 \%, \mathrm{n}=17)$ were $18-25$ years old and female $(77.8 \%, \mathrm{n}=21)$. Non-health related majors accounted for $55.6 \%$ of the participants, $74.1 \%$ were single, and $81.4 \%$ reported they had no children. Most participants $(66.7 \%$, $\mathrm{n}=18$ ) reported no history of health conditions. However, the most commonly reported health conditions were 
respiratory $(14.8 \%, n=4)$, and gastrointestinal $(14.8 \%, n=4)$.

Table 1. Demographic Information

\begin{tabular}{|c|c|c|}
\hline & $n$ & $\%$ \\
\hline \multicolumn{3}{|l|}{ Age } \\
\hline $18-25$ & 17 & 62.9 \\
\hline $25-55$ & 8 & 29.6 \\
\hline$>55$ & 2 & 7.4 \\
\hline \multicolumn{3}{|l|}{ Gender } \\
\hline Male & 6 & 22.2 \\
\hline Female & 21 & 77.8 \\
\hline \multicolumn{3}{|l|}{ Education Level } \\
\hline Some College & 17 & 63 \\
\hline College Graduate & 1 & 3.7 \\
\hline Graduate Degree & 7 & 25.9 \\
\hline $\mathrm{PhD}$ & 2 & 7.4 \\
\hline \multicolumn{3}{|l|}{ Major/Discipline } \\
\hline Health Related & 12 & 44.4 \\
\hline Non-Health & 15 & 55.6 \\
\hline \multicolumn{3}{|l|}{ Marital Status } \\
\hline Single & 20 & 74.1 \\
\hline Marricd & 6 & 22.2 \\
\hline Widowed & 1 & 3.7 \\
\hline \multicolumn{3}{|l|}{ Children } \\
\hline Ycs & 5 & 18.5 \\
\hline No & 22 & 81.4 \\
\hline \multicolumn{3}{|l|}{ Health } \\
\hline Cardiovascular & 2 & 7.4 \\
\hline Respiratory & 4 & 14.8 \\
\hline Gastrointestinal & 4 & 14.8 \\
\hline Renal & 0 & 0.0 \\
\hline Neurological & 2 & 7.4 \\
\hline Musculoskeletal & 2 & 7.4 \\
\hline Other & 2 & 7.4 \\
\hline None & 18 & 66.7 \\
\hline
\end{tabular}

\section{PRODUCT USE}

See Table 2 for personal care product use and Table 3 for household cleaning product use. Information included in both Table 2 and Table 3 came from baseline surveys, and items are grouped by category (i.e. "lip balm," "lip gloss," and "chapstick" all constituted as lip balm). Participants reported more personal care product use $(63 \%$, $n=17)$ than household cleaning product use $(40.7 \%, n=11)$. The most commonly used personal care products included shampoo (81.4\%, $n=22)$, body wash $(62.9 \%, n=17)$, and "make-up" $(59.3 \%, n=16)$. The most commonly used household cleaning products included dish soap $(44.4 \%, n=12)$, laundry detergent $(25.9 \%, n=7)$, and all-purpose cleaner $(25.9 \%, n=7)$.

\section{PRIOR EDUCATION AND INTENT TO ACT}

Of the 27 participants, $81.5 \%(n=22)$ reported no prior $\mathrm{EH}$ education, indicating a lack of EHL among the target population. Prior to the education session, $77.8 \%(n=21)$ indicated awareness of natural alternatives, whether that was hearing about the products or considering using the products. As a result of education, $48.1 \%(n=13)$ of participants stated they would use the information to educate and inform others on the topic of $\mathrm{EH}$, thus encouraging the diffusion of innovations among a larger group, while $66.7 \%(n=18)$ of participants stated they would use the information in their daily lives to make a change.

\section{BARRIERS TO EHL}

During group discussion after education, 37\% $(n=10)$ of participants indicated that lack of education was a major barrier to their ability to make informed decisions when purchasing personal care and

household cleaning products, suggesting the need for more education among this population. Other key barriers to applying EHL in daily life included convenience $(40.7 \%, n=11)$, cost $(33.3 \%, n=9)$, and brand familiarity and availability $(29.6 \%, \mathrm{n}=8)$. In the subsections that follow, participant quotes addressing barriers to EHL are highlighted. Quotes are representative of participants' responses for each of the identified categories.

\section{Education}

Participants expressed that they had "very little knowledge," and that they "didn't realize it was such a big burden on the health of our environment, and human health." Another participant noted the divide between education on household cleaning products versus personal care products. They stated that they "knew a little about cleaning supplies, because that's just kind of obvious... but with personal care products... that's something I could definitely spread the word on." Along with education, one participant cited "ignorance" as a major barrier, because "a lot of people are just unwilling to cooperate." Similarly, one participant said they “just didn't understand... how affected we were on a daily basis." After education, a participant stated that "now that I know how easy it is to make a safe product, it's not so daunting."

\section{Convenience}

Convenience was another major barrier. One participant stated that "time would be a deterrent... to research [products]." However, participants stated that the folder they received containing resources for further information was helpful, as it would minimize time spent researching. They noted "I feel well prepared, especially 
with the website," and "I feel much more mindful and well prepared with the sources [the researcher] gave me." The barrier of convenience is significant, so much so that for one participant, convenience was more important than health: the participant said that "it's easier to pick something up [that] I know is not safe [than to search for alternatives]."

An interesting topic brought about during discussion was that of inconvenient disposal. After the presentation, a participant asked about disposal of products, which was mentioned in the education session, because "now that we're aware... we're trying to get some of these products out of our home." In response, one participant said "they make [disposal] very inconvenient." Another participant responded, noting that there "is only one location in Fort Worth."

Table 2. Personal Care Product

\begin{tabular}{|c|c|c|}
\hline Personal Care Product & $N$ & $\%$ \\
\hline Shampoo & 22 & 81.4 \\
\hline Lip Balm & 21 & 77.8 \\
\hline Body Wash & 17 & 62.9 \\
\hline Make-up & 16 & 59.3 \\
\hline Lotion & 14 & 51.9 \\
\hline Deodorant & 9 & 33.3 \\
\hline Face wash & 8 & 29.6 \\
\hline Toothpaste & 7 & 25.9 \\
\hline Hairspray & 5 & 18.5 \\
\hline Hand Soap & 5 & 18.5 \\
\hline Cologne'perfume & 4 & 14.8 \\
\hline Cologneiperfume & 4 & 14.8 \\
\hline Mouthwash & 2 & 7.4 \\
\hline Misc. skin products & 2 & 7.4 \\
\hline Contact solution & 1 & 3.7 \\
\hline Make-up remover & 1 & 3.7 \\
\hline Sunsereen & 1 & 3.7 \\
\hline
\end{tabular}

Table 3. Household Cleaning Product Use

\begin{tabular}{|c|c|c|}
\hline Household Cleaning Product & $n$ & $\%$ \\
\hline Dish soap & 12 & 44.4 \\
\hline Laundry detergent & 7 & 25.9 \\
\hline All-purpose cleaner & 7 & 25.9 \\
\hline Cleaning wipes & 7 & 25.9 \\
\hline Hand soap & 5 & 18.5 \\
\hline Blcach & 4 & 14.8 \\
\hline Gilassimirror clcancr & 4 & 14.8 \\
\hline Dishwashing detcrgent & 3 & 11.1 \\
\hline Other & 3 & 11.1 \\
\hline Air freshener & 2 & 7.4 \\
\hline Baking soda & 2 & 7.4 \\
\hline
\end{tabular}

Cost

Another barrier, cost, was a concern for participants. A participant stated that "many times price [is a barrier]". Another stated that certain grocery store's "line[s] of household products is very expensive." When considering alternative cleaning products as a whole, a participant noted that "expense [as] a common theme with the organics." It is interesting to highlight responses that noted cost and convenience. One participant said "it's not that I can't afford it, but I go to the store quickly and I buy what I'm used to buying." Another participant said "it's sometimes more expensive to go the organic way, so you kind of just go default." These responses may indicate a connection between cost and convenience.

\section{Brand Familiarity and Availability}

Finally, participants cited brand familiarity and availability as a major barrier, stating, "we're just used to going and seeing the familiar [brand] and picking it out, not really caring about what the other products are." Another participant responded, saying "the main brands just take over." Convenience and time may factor into brand familiarity, as one participant said "I don't really sit there and look at all of the different products... I just see the ones I usually use." Another participant responded, stating "maybe it's the stores I shop at that [alternative products are] not available." Interestingly, one participant noted that brand familiarity was important not just to the participant, but to their family,

saying "family member pushback might be an issue. Whenever I buy something different... like organic mustard, the family was just like, 'No, it doesn't taste as good!'”

\section{Expressed Commitment to Action}

An estimated $95 \%$ of participants felt the lesson motivated them to make informed choices and educate others. In order to make informed decisions, one participant cited the EWG databases that the researcher 
provided as "such a good resource." Another responded, "I'm going to go look at it now." Educating others, mainly family members and peers, was another widely expressed commitment to action among participants. One participant said, "sharing the website, I think that's an important thing to do for folks that I know with health issues... I'm going to snap [the handout] and send it to [my friend with health issues]." One student participant stated "my parents use [hazardous] stuff like this... so I guess I could help them find better alternatives." Another participant built on this statement, stating "I'm going to try to inform others and $100 \%$ incorporate it in my daily life somehow."

\section{DISCUSSION}

Evaluation of data yielded information consistent with previously reviewed literature. Results reiterated the need for EHL among the target population, as participants consistently identified lack of understanding and education on the topic of environmental health as a major barrier to making informed decisions when purchasing products. Participants' action-oriented responses to group discussion indicated EH sessions were effective in not only equipping participants with relevant information on $\mathrm{EH}$, but also encouraging participants to apply the information to daily life and take action. Beyond individual change, participants' desire to educate others, including family and friends, indicates that providing this population with education equips them with the ability to spread the information across a larger population, thus encouraging diffusion of innovation in regard to EHL among the campus community.

Because the population was $77.8 \%$ female, it may be important to include more information about risks associated with personal care and household cleaning products during pregnancy and breastfeeding in future education sessions. In addition, focus on personal care product dangers over household cleaning products may prove beneficial, as the majority of products reported on the baseline survey were personal care products. In addition, participant responses indicated more knowledge about household cleaning product hazards over personal care products.

It is important to note that the majority of participants $(66.7 \%, \mathrm{n}=18)$ did not suffer from any health conditions, yet the majority of participants expressed intent to take action to reduce use of potentially hazardous products in order to prevent health complications. This finding strengthens previous research showing that groups similar to the target population, namely young adults, are concerned with pollution and environmental hazard impact on the health of individuals and their families (Cutchin et al., 2008).

Among participants with health conditions, the most common conditions reported were respiratory and gastrointestinal. These conditions, namely respiratory, are often aggravated by potentially hazardous products, like aerosols and fumes from household cleaning products, such as bleach. Because these conditions are most common among the target population, it may be useful to include more information during education sessions that focuses on respiratory and gastrointestinal effects of potentially hazardous products. This information could encourage those with these health conditions to reconsider product use and move toward natural alternatives, thus reducing the impact to their health and potentially reducing exacerbating influences of their illness.

\section{Limitations}

Limitations of the study included a small sample size, limited data measurements, self-reported data, and social desirability. There were 27 participants in the study, which provides limited information that cannot necessarily be applied across the entire TCU campus population or other campuses. It may be assumed that those who participated already had interest in EHL, thus influencing their responses. In addition, a lack of instruments to measure EHL is a limitation to investigators who are interested in this field of study. More relevant data on EHL may have emerged before and after the education session had more knowledge questions been included in the pre-survey and the group discussion. Furthermore, because participants were among peers, there was a high possibility of social desirability bias, especially among student participants, as the sessions were peer-led.

\section{Implications for Research}

As a result of this study, further research should focus on finding effective strategies to promote, retain, apply, and measure EHL among the general public. This could include education campaigns, or required education 
campaigns, or required education sessions for students, faculty, and staff on college campuses. An evaluation of the effects of industrial cleaning on the TCU campus may provide new insight into the more widespread effects of potentially hazardous chemicals on the campus population, as these are exposures individuals cannot control without administrative intervention on the campus level.

A follow-up study may be beneficial to evaluate whether or not EH education sessions prompted personal change, and if any information was disseminated to participants' family, friends, or colleagues. Participants noted that it may be helpful for TCU to provide incoming freshmen "with literature... [and] give everybody a little packet of sample [natural] products." When carrying out further EHL research on the TCU campus, this approach could be highly beneficial, as it targets a larger group of people and can provide a better understanding of the campus attitude toward natural alternatives.

At the 2014 Partnerships for Environmental Public Health (PEPH) Annual Meeting, representatives from across the nation came together with the purpose of advancing EHL by using communication research to explore tools and strategies to improve EHL. In conducting future studies, communication research is an important aspect to incorporate. According to the National Institute of Environmental Health Sciences (NIEHS), collaborative, interprofessional communication research is a "foundation for building EHL.... Environmental health scientists can advance EHL by collaborating with scholars from departments/schools of communication, anthropology, sociology, psychology, education, and public health. (p.5)" This recommendation is significant, as further research on university campuses, like TCU, can enhance the underdeveloped field of EHL.

\section{Implications for Practice}

Results from this study raise important implications not only for nursing practice, but also in other clinical fields, both in promoting health and reducing costs to patients and hospitals. As previously mentioned, personal care products and household cleaning products are particularly dangerous for those with respiratory issues. Fumes and aerosolized products can exacerbate existing conditions, like Chronic Obstructive Pulmonary Disease (COPD) and asthma. These products can also cause long-term damage to lung cells, potentially contributing to the burden of respiratory disease that is already prevalent in the U.S. If hospitals encouraged nurses, who carry out the majority of bedside education to patients, to teach patients, particularly patients and families with existing health conditions, about natural alternatives to particularly irritating products, readmission rates and exacerbations may decrease. This not only benefits the patient through improved health and fewer healthcare costs, but it also benefits hospitals, as reimbursement would increase following decreases in readmission rates.

EH education could benefit all patients, as they could prevent potential negative health outcomes, like new onset of disease, as well as reduce costs to the patients, as it is relatively cheap to make a natural all-purpose cleaner. This especially benefits low-income patients, who are already at increased risk for disease due to stressful conditions, lack of access to healthcare, and poor nutrition. By using a do-it-yourself alternative, these low-income patients could save money and be encouraged to keep their homes clean, leading to a healthier living environment while saving money. In this way, nurses in all settings could act to improve public health as a whole by addressing the socioeconomic concerns of the patient as it applies to promoting a clean, healthy living space.

\section{A call to action for clinicians: precautionary principle as policy}

When applying the findings of this study on a larger scale in terms of environmental policy and public health, an important concept to consider is precautionary principle, explored in detail in the literature review. One of the principles of public health nursing is the concept of primary prevention, or preventing the problem before it begins. One such method of primary prevention comes from the Health Impact Pyramid (Frieden, 2010). The pyramid evaluates interventions ranging from the top of the pyramid, counseling and education-which has the smallest impact - to the bottom, socioeconomic factors, which has the broadest impact. Precautionary principle targets the intervention with the second broadest impact, "changing the context to make individuals' default decisions healthy," (Frieden, 2010, p. 591).

In 2003, the ANA adopted the precautionary principle as it applies to healthcare. The ANA decided to "broaden its work in occupational and environmental health and apply a precautionary approach when an activity 
raises threats of harm to human health or the environment," (ANA, 2007, p. 6). In addition, they agreed to "advocate for public policy that utilizes the precautionary approach that focuses on prevention of hazards to people and the natural environment," (ANA, 2007, p. 6). Nurses, as well as other healthcare professionals, can create immense change by supporting precautionary principle as standards of practice. By pushing public policy makers to eliminate all chemicals that have the potential to be harmful, or are known to be harmful, the public's default decision is the healthy decision, as they no longer have the option to buy unhealthy products. As nurses, educating patients and creating a group of concerned and motivated individuals can help to promote the use of precautionary principle in the U.S., a concept that is not currently employed in this country.

\section{CONCLUSIONS}

Through educating students, faculty, and staff on the TCU campus on environmental health and risks associated with everyday products, individuals have the ability to effect change within the campus community, as well as the community at large. The outcome of this study has the potential to effect individual action and support policy changes regarding environmental health exposures, thus benefiting students and faculty on the TCU campus both now and in the future. 


\section{REFERENCES}

Agency for Toxic Substances and Disease Registry. Environmental Health: Preventing Exposureto Hazardous Substances. 2014. PowerPoint Presentation. Web.

American Nurses Association. ANA's Principles of Environmental Health for Nursing Practice with Implementation Strategies.American Nurses Association: Silver Spring, MD. Nursebooks. 2007. Web. http://www.nursing world.org/MainMenuCategories/WorkplaceSafety/Healthy-Nurse/ANAsPrinciplesofEnvironmentalHealthfor NursingPractice.pd.

Banerjee, Rajdeb and Pallav Sengupta. "Environmental toxins: Alarming impacts of pesticideson male tertility. Human and Experimental Toxicology.33.10 (2014): 1017-39. http://dx.doi.org/10.1177/0960327113515504.

Barrett, R., Chan, L.M., \& Chalupka, S.M. Female College Student Awareness of Exposures to Environmental Toxins in Personal Care Products and their Effect on Preconception Health. Workplace Health \& Safety, 63(2), 64-70. http://dx.doi.org/10.1177/2165079914565347

Bondi, C.A.M. (2010). Applying the precautionary principle to consumer household cleaning product development. Journal of Cleaner Production, 19, 429-437. http://dx.doi.org/10.1016/j.jclepro.2010.07.008

Brown, S.L., Middleton, W.K., Ratnapradipa, D., \&Wodika, A.B. (2011) Measuring environmental health perception among college students. The Health Educator, 43(2), 13-20. Retrieved from http://eric.ed.gov/?id=EJ967821

Corvalán, C.F, Kjellström, T., Smith, K.R. (1999). How much global Ill health is attributable to environmental factors? Epidemiology, 10(5), 573-584. http://dx.doi.org/10.1097/00001648-199909000-00027

Cutchin, M. P., Goodwin, J. S., Martin, K. R., Owen, S. V. (2008). Concern about petrochemical health risk before and after a refinery explosion. Risk Analysis, 28(3), 589-601. http://dx.doi.org/10.1111/j.1539-6924.2008.01050.x

Dixon, J.K., Dixon, J.P., Ercolano, E., Hendrickson, K.C., Quackenbush, R. (2009). The environmental health engagement profile: What people think and do about environmental health. Public Health Nursing, 26(2), 460-473. http://dx.doi.org/10.1111/j.1525-1446.2009.00804.x

Edris, A.E. (2007). Pharmaceutical and therapeutic potentials of essential oils and their individual volatile constituents: A review. Phytotherapy Research 21(4),308-323. http://dx.doi.org/10.1002/ptr.2072

Environmental WorkingGroup. (2017). EWG's Guide to healthy cleaning. Environmental Working Group. Web. https:// www.ewg.org/guides/cleaners\#.WhiajFWnGUkEnvironmental Working Group. (2017). Skin deep. Environmental Working Group. http://www.ewg.org/skindeep/

Finn, S.\&O'Fallon, L. (2015). The emergence of environmental health literacy-From its roots to its future potential. Environmental Health Perspectives. http://dx.doi.org/10.1289/ehp.1409337

Frieden, T.R. (2010). A framework for public health action: The health impact pyramid. American Journal of Public Health, 100(4), 590-595. http://dx.doi.org/10.2105/AJPH.2009.185652

Glegg, G.A., Richards, J.P. (2007). Chemicals in household products: Problems with solutions. Environmental Management, 40, 889-901. http://dx.doi.org/10.1007/s00267-007-9022-1

Kriebel, D., Tickner, J., Lemons, R., Levins, R., Loechler, E.L., Quinn, M., Rudel, R., Schettler, T., Stoto, M., 2001. The precautionary principle in environmental science. EnvironmentalHealth Perspectives, 109(9), 871-876.

Lanphear, B.P. (2015). The Impact of Toxins on the Developing Brain. The Annual Review of Public Health, 36, 211-30. http://dx.doi.org/10.1146/annurev-publhealth-031912-114413 
National Institute of Environmental Health Sciences. (2014). Environmental health literacy: The evolution of a new field. National Institute of Environmental Health Sciences. https://www.niehs.nih.gov/research/supported/ translational/peph/webinars/health_literacy/

Pender, N.J.(1982). Health Promotion in Nursing Practice. Norwalk, CT: Appleton-Century-Crofts.

Raffersperger, C., Tickner, J. (Eds.), 1996. Protecting public health and the environment: implementing the precautionary principle.Environmental Practice. 2(1), 106-107http://dx.doi.org/10.1017/s1466046600001186

Rogers, E.M. (1962). Diffusion of Innovations. New York, NY: Free Press.

Severtson, D.J. (2013). The influence of environmental hazard maps on risk beliefs, emotion, and health-related behavioral intentions. Research in Nursing \& Health, 36, 330-348. http://dx.doi.org/10.1002/nur.21544

Xu, J., Zhou, F., Ji, B.P., Pei, R.S., Xu, N., 2008. The antibacterial mechanism of carvacrol and thymol against escherichia coli. Letters in Applied Microbiology 47(3), 174-179. http://dx.doi.org/10.1111/j.1472-765X.2008.02407. xAgency for Toxic Substances and Disease Registry. Environmental Health: Preventing Exposureto Hazardous Substances. 2014. PowerPoint Presentation. Web. 